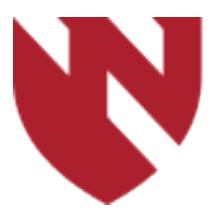

September 2020

\title{
Running Miles without the Smiles; an Exploration of Alternative Treatment
}

Peter M. Martin

University of Nebraska Medical Center

Rebecca L. Peebles

University of Nebraska Medical Center

Tell us how you used this information in this short survey.

Follow this and additional works at: https://digitalcommons.unmc.edu/gmerj

Part of the Higher Education Commons, and the Medicine and Health Sciences Commons

\section{Recommended Citation}

Martin, P. M., , Peebles, R. L. Running Miles without the Smiles; an Exploration of Alternative Treatment. Graduate Medical Education Research Journal. 2020 Sep 29; 2(1).

https://digitalcommons.unmc.edu/gmerj/vol2/iss1/70

This Conference Proceeding is brought to you for free and open access by DigitalCommons@UNMC. It has been accepted for inclusion in Graduate Medical Education Research Journal by an authorized editor of DigitalCommons@UNMC.For more information, please contact digitalcommons@unmc.edu. 


\section{Running Miles without the Smiles; an Exploration of Alternative Treatment}

Creative Commons License

(c) 1 (1) (अ)

This work is licensed under a Creative Commons Attribution-Noncommercial-No Derivative Works 4.0 License. 
only 3 reached statistical significance (IL-10, IP-10, TNF $\alpha$ ), and none were significantly greater in OA vs. RA.

Conclusion: Although this commercially available multiplex assay generally performed well in the context of RA, interference induced by RF meaningfully impacted the quantification of one in five analytes examined.

https://doi.org/10.32873/unmc.dc.gmerj.2.1.066

\section{Running Miles Without the Smiles; an Exploration of Alternative Treatment \\ Peter M. Martin ${ }^{1}$, Rebecca L. Peebles ${ }^{1}$}

${ }^{1}$ University of Nebraska Medical Center, Department of Family Medicine and Offutt Airforce Base

Mentor: Rebecca L. Peebles

Program: Family Medicine

Type: Case Report

Background: A 42-year-old male presented to sports clinic with bilateral anterolateral lower leg pain for 1.5 years. Pain is exacerbated by running with associated painful swelling and "small bulges" along the anterolateral legs. Symptoms arise within 8 minutes of activity and cease within 5-10 minutes of rest. Physical therapy was unsuccessful.

\section{Methods:}

- Bilateral Lower Extremity Exam:

»Inspection: Normal

» Palpation: Normal

»ROM: Normal

» Special Tests: Resisted ROM testing and tuning fork exam normal

- Bilateral LE X-ray and MRI: normal

»Compartment Pressure Testing: See Table 1

» Elevated post-exercise compartment pressures noted

»With exercise, $2 \mathrm{~cm}$ tender bulge present on lateral lower legs bilaterally
Results: The patient's final diagnosis was bilateral chronic exertional compartment syndrome (CECS) with associated fascial hernias. After counseled on treatment options including gait retraining, botulinum toxin injections, and fasciotomy, he received 50 units botulinum toxin at each legs' anterior and lateral compartments. Within 3 weeks he reported $70 \%$ improvement and later completed gait retraining without pain.

Conclusion: Lower extremity fascial hernias may present with or without CECS symptoms. CECS is reversible, exercise induced ischemia at a predictable level of exercise due to noncompliant osseofascial compartments. Numerous cases support botulinum toxin injections for CECS, but little evidence exists for its use in fascial hernias. This sparks the question if compartment testing and botulinum toxin treatment should be considered for all fascial hernias, including those without CECS symptoms. With physical therapy and gait retraining, this offers an alternate approach to fasciotomy.

https://doi.org/10.32873/unmc.dc.gmerj.2.1.067

\section{Table 1.}

Compartment testing before and after exercise (in $\mathrm{mm} \mathrm{Hg}$ ).

\begin{tabular}{lcccc} 
& $\begin{array}{c}\text { Pre-Exercise } \\
\text { Left Leg }\end{array}$ & $\begin{array}{c}\text { Post-Exercise } \\
\text { Left Leg }\end{array}$ & $\begin{array}{c}\text { Pre-Exercise } \\
\text { Right Leg }\end{array}$ & $\begin{array}{c}\text { Post-Exercise } \\
\text { Right Leg }\end{array}$ \\
\hline Anterior & 11 & 81 & 12 & 30 \\
\hline Lateral & 18 & 35 & 17 & 22 \\
\hline Deep Posterior & 7 & 26 & 6 & 7 \\
\hline Superficial Posterior & 13 & 19 & 10 & 20 \\
\hline
\end{tabular}

\section{Anesthetic Considerations for Sjögren-Larsson Syndrome \\ Maireen Miravite ${ }^{1}$, Michelle LeRiger ${ }^{1}$, Marcellene Franzen ${ }^{1}$, Kaitlyn Pellegrino}

${ }^{1}$ University of Nebraska Medical Center, Department of Anesthesiology

Mentor: Michelle LeRiger, Marcellene Franzen, Kaitlyn Pellegrino

Program: Anesthesiology

Type: Case Report

Background: Sjögren-Larsson syndrome (SLS) is a rare autosomal recessive neurocutaneous disorder caused by a mutation in the gene encoding fatty aldehyde dehydrogenase. SLS is characterized by eneralized ichthyosis, seizures, cognitive disability, spasticity, and ophthalmologic changes. Limited resources are available to guide anesthetic management for patients with SLS. This case series seeks to identify anesthetic considerations in patients with SLS.

Methods: After IRB approval, a chart review of anesthetic records of SLS patients from February 2013 to October 2019 was conducted. Data included age, gender, relevant comorbid conditions
(Table 1), induction and maintenance agents, intravenous and oral analgesics, muscle relaxants, procedure performed, and complications.

Results: A total of 14 patients undergoing 47 anesthetic cases were identified. Cases included brain MRI, botulinum toxin injection, tendon release, and dental restoration. General anesthesia was performed for nearly all procedures. The most common observations were related to ichthyosis, including difficulty 